\title{
Secretory process: the role of age, autoimmunity and endocrinopathy
}

\author{
Antonina Mistretta', Viola Pasquale², Davide Pisani², Marco Ciriolo², \\ Riccardo Speciale ${ }^{1}$, Giuseppe Chiarella² \\ ${ }^{1}$ Department of Biomedicine, Neurosciences and Advanced Diagnostics, Section of ENT Surgery, \\ University of Palermo, Italy; ${ }^{2}$ Department of Experimental and Clinical Medicine, Audiology and \\ Phoniatrics Unit, Magna Graecia University, Catanzaro, Italy
}

Received: April 20, 2020

Accepted: June 3, 2020

\section{Correspondence \\ Viola Pasquale \\ Department of Experimental and Clinical Medicine, Audiology and Phoniatrics Unit, Magna Graecia University, Campus S. Venuta, viale Europa 88100, Catanzaro, Italy \\ E-mail: pasqualeviola@unicz.it}

\section{Conflict of interest}

The Authors declare no conflict of interest

How to cite this article: Mistretta $A$, Pasquale V, Pisani D, et al. Secretory process: the role of age, autoimmunity and endocrinopathy. Journal of Gerontology and Geriatrics 2020;68:99-105. https:// doi.org/10.36150/2499-6564-487

C Copyright by Società Italiana di Gerontologia e Geriatria (SIGG)

\section{(c) (1) (3) $(9$}

This is an open access article distributed in accordance with the CC-BY-NC-ND (Creative Commons Attribution-NonCommercial-NoDerivatives 4.0 International) license. The article can be used by giving appropriate credit and mentioning the license, but only for non-commercial purposes and only in the original version. For further information: https://creativecommons.org/licenses/by-nc-nd/4.0/deed.en
Xerostomia is a common occurrence in older people, impairing their quality of life. When salivary gland function goes below $50 \%$, patients show oral mucosal dryness and consequent problems on speaking and eating. They present oral health impairment. Their quality of life is compromised too. The prevalence of xerostomia is reported to be approximately $30 \%$ in people over 65 years old. Drug-induced xerostomia is the most common cause of dry mouth in elderly, because many older adults are taking at least one medication that causes salivary dysfunction. Among the autoimmune disease that can cause xerostomia, Sjögren's syndrome (SS) is the most representative one in elderly. Dryness of oral mucosa and eyes is the main symptom of the disease. The "Elderly onset primary Sjogren's Syndrome" (EopSS) is a common disease in Caucasian population, with a global incidence of $3 \%$ but a geographic variability. Patients with SS are frequently misdiagnosed, and physicians treat each symptom individually, unaware of underlying systemic disease. The control of symptoms with substitution of saliva and tears is recommended; therapies with anti-CD20 and Interferon- $\alpha$ are useful in patients with residual glandular function and salivary flow. Among the endocrinopathies, diabetes mellitus (DM) is the most common cause of xerostomia in older patients. Hyposalivation increases in diabetic patients with low metabolic control, which can cause more severe side effects in relation to oral health. Xerostomia may be produced by changes in salivary composition (caused by diabetes complications such as neuropathy, angiopathy, and metabolic failure) instead of changes in salivary quantity. Treating diabetes itself, maintaining good glycaemic values, can allay xerostomia in those patients. Doctors and dentists have to be aware of the various oral manifestations of diabetes in order to make an early diagnosis and treatment, avoiding further complications.

Key words: xerostomia, dry-mouth, autoimmunity, Sjögren's syndrome, diabetes, oral-pharyngeal health, secretory flow

The production of saliva is the main secretive process affected by agerelated alterations of the immune system. While saliva plays a key role in preserving oral-pharyngeal health, the complaint of a dry mouth (i.e. xerostomia) and the objective finding of salivary dysfunction is a common occurrence in older individuals, producing transient and permanent oral and systemic problems that are as broad as impaired food and beverage 
intake, altered host defence, and oral communication; Untreated xerostomia significantly impairs the quality of life ${ }^{1}$ due to its link to a number of conditions and downstream symptoms (Tab. I).

\section{XEROSTOMIIA IN GERIATRIC PATIENTS}

Generally, the salivary function remains remarkably intact in healthy older people who are not being treated for medical problems or receiving pharmacological therapy. Salivary constituents appear to be age-stable in the absence of major medical problems and medications. There is a general agreement that values below $45 \%$ of unstimulated fluid secretion could be used as a cut off to define salivary hypofunction ${ }^{2}$, and that with a glandular fluid production decreased by about $50 \%$, a person will begin to experience symptoms of oral dryness ${ }^{3}$. The prevalence of xerostomia increases with age and is reported to be approximately $30 \%$ of the population aged 65 and older ${ }^{4}$. Drug-induced xerostomia is the most common cause, because many older adults are taking at least one medication that causes salivary dysfunction ${ }^{5}$. However, it is difficult to estimate the true prevalence of xerostomia in older adults taking medications. In addition, radiation therapy to the head and neck for the treatment of cancer causes permanent xerostomia and has a $100 \%$ prevalence rate ${ }^{6}$. The latter should not be underestimated since 1.2\% percent of all men and women will be diagnosed with oral cavity and pharynx cancer at some point during their lifetime, based to the 2016 SEER statistics (https://seer.cancer. gov/statfacts/html/oralcav.html).

Numerous systemic diseases and their treatments (medications, head and neck radiation, chemotherapy) contribute significantly to salivary gland dysfunction in older people ${ }^{4}$ (Tab. II). Among the other autoimmune diseases, like Sjögren's syndrome (SS), scleroderma, sarcoidosis, lupus, graft versus host disease are common causes of xerostomia in elderly patients. It is important to note that the prevalence of xerostomia is nearly $100 \%$ among SS patients, an autoimmune exocrinopathy affecting between 1 and $4 \%$ of older adult populations ${ }^{7}$.

\section{IMMUNOSENESCENCE}

There is a progressive impairment of the immune system associated with aging; specifically, there is a reduction in the naive lymphocytes pool, and an increase in the number of memory lymphocytes. Neutrophils show a slower reaction to chemotactic stimuli and reduced phagocytic competence. In this age group, the relatively preserved innate response generally overrides the more altered adaptive immune response, resulting in higher production of pro-inflammatory mediators. This concept suggested that aging might be potentially associated with a chronic, sterile, often subclinical, lowgrade inflammation.

Antinuclear Antibodies (ANA) and other autoantibodies count often become higher with aging, without showing a precise pathologic meaning. Indeed, despite the augmented prevalence of autoantibodies in subjects over the age of 75 , incidence of autoimmune pathology (e.g. Lupus) is less frequent than in other age groups ${ }^{8}$.

Table I. Consequences of decreased salivary function.

\begin{tabular}{|l|}
\hline $\begin{array}{l}\text { Decreased salivary function: } \\
\text { oral and pharyngeal consequences }\end{array}$ \\
\hline Dryness lips and mouth \\
\hline Traumatic oral lesions \\
Dental caries \\
Oral-pharyngeal infections (candidiasis) \\
Dysgeusia \\
\hline Mastication problems and dysphagia \\
\hline Gingivitis \\
\hline Halitosis \\
\hline Mucositis \\
\hline Poorly fitting denture \\
\hline Sleep problems \\
\hline Speech difficulty \\
\hline
\end{tabular}

Table II. Causes of xerostomia in geriatric patients: bold characters are for autoimmune diseases.

\begin{tabular}{|c|c|}
\hline \multicolumn{2}{|c|}{ Causes of xerostomia in geriatric patients } \\
\hline Causes & Examples \\
\hline Treatments & $\begin{array}{c}\text { Anticholinergics (ACH) } \\
\text { Tricyclic antidepressants (TCA) } \\
\text { Sedatives } \\
\text { Antihistamines } \\
\text { Antihypertensives } \\
\text { Anti-Parkinsonian drugs } \\
\text { Antiseizure drugs } \\
\text { Skeletal muscle relaxants } \\
\text { Cytotoxic agents } \\
\text { Head and neck radiotherapy }\end{array}$ \\
\hline Oral pathology & $\begin{array}{c}\text { Parotitis } \\
\text { Sialolithiasis } \\
\text { Salivary obstruction }\end{array}$ \\
\hline $\begin{array}{l}\text { Systemic } \\
\text { conditions }\end{array}$ & $\begin{array}{c}\text { Sjogren's syndrome } \\
\text { Scleroderma } \\
\text { Lupus } \\
\text { Sarcoidosis } \\
\text { GvHD } \\
\text { Diabete mellitus } \\
\text { HIV/AIDS } \\
\text { Mumps } \\
\text { Alzheimer's disease } \\
\text { Dehydratation }\end{array}$ \\
\hline
\end{tabular}




\section{SJÖGREN'S SYNDROME IN THE ELDERLY}

The most interesting autoimmune disease for its role on secretory function in the elderly is the Sjogren syndrome (SS). In the elderly population, this disease may present a typical clinical pattern. SS belongs to a group of connective-tissue autoimmune diseases. Dryness of oral mucosa and eyes is the most common and most recognisable symptom of the disease. There are two forms of the disease: primary (pSS) and secondary Sjögren's syndrome (sSS). pSS has precisely defined diagnostic classification criteria aiming to exclude disorders that might imitate pSS, such as active hepatitis C, IgG4-dependent disease, or sarcoidosis, in the absence of other systemic connective tissue diseases. On the other hand, when symptoms of SS coexist with another systemic connective tissue disease, a secondary SS diagnosis should be evaluated. SSS is often identified focusing on the symptoms of dryness in the presence of other connective tissue disease, making the diagnosis of sSS quite subjective ${ }^{9}$.

Given this issue, in 2019, Mavraganiet and Moutsopoulos proposed that the terms "primary" and "secondary" SS should be replaced by a more descriptive terminology: SS when the disease is expressed as an entity alone or "SS associated with systemic or organ-specific autoimmune diseases", provided that, in all cases, the set of criteria for SS are fulfilled ${ }^{10}$. Classification criteria ${ }^{9}$ have been effective since 2016 (Tab. III). They constitute a consensus of the previous criteria and are the most objective of all proposed to date, due to exclusive use of objective methods, such as histopathological examination of labial salivary gland, Schirmer's test, staining of the eye with Rose Bengal, or assessment of unstimulated salivary flow. Only the Anti-SS related antigen (SS-A/Ro) levels and minor salivary gland biopsy play a primary role in the diagnostic process, while Schirmer's test, ocular Staining Score, unstimulated total salivary excretion, van Bijsterveld's Score have a secondary role.

Epithelial damage, autoantibodies production and

Table III. Current classification criteria for SS.4 point are needed to diagnose SS, but specificity increases from 89 to $98 \%$ using a 5 points cut-off (from Vitali, Del Papa, 2017, mod.) ${ }^{11}$.

\begin{tabular}{|l|c|}
\hline Classification criteria for SS & Score \\
\hline Schirmer test $<5 \mathrm{~mm} / 5 \mathrm{~min}$ in at least one eye & 1 \\
\hline $\begin{array}{l}\text { Ocular Staining Score } \geq 5 \text { (or van Bijsterveld's Score } \geq 4 \text { ) } \\
\text { in at least one eye }\end{array}$ & 1 \\
\hline Unstimulated total salivary excretion $<0.1 \mathrm{ml} / \mathrm{min}$ & 1 \\
\hline Anti-SS-A/Ro antibodies & 3 \\
\hline $\begin{array}{l}\text { Labial salivary gland biopsy showing focal lymphocytic } \\
\text { sialadenitis and focus score } \geq 1 / 4 \mathrm{~mm}^{2}\end{array}$ & 3 \\
\hline
\end{tabular}

activation of innate and adaptive immune response are crucial events into pSS pathogenesis. There is an infiltration of the glandular tissue with predominantly CD4+ T lymphocytes, B lymphocytes and dendritic cells by epithelial cell proliferation and apoptosis. B-Lymphocytes are of key importance in producing auto-antibodies like ANA, ENA and SS-A/Ro - SSA/La, which appear later in the disease presentation ${ }^{12}$. Autoimmunity can be favoured by antigenic mimicry (autoantibodies similar to hetero-antibodies, like EBV-antibodies) ${ }^{13}$. The "Elderly onset primary Sjogren's Syndrome" (EopSS) is a common disease in caucasian population, strongly predominant in female (9:1) and has a global incidence of $3 \%$, varying by geographic areas and diagnostic capabilities ${ }^{14}$. An Italian cohort-study evidenced an overall incidence of $6 \%{ }^{15}$. In our clinic we observed that about $10 \%$ of the suspected SS patients undergoing salivar glands biopsy for diagnosis are over 65 years old, with a confirmation of such diagnosis in about $50 \%$ of the cases. Overall, taking into account that EopSS could be mainly subclinical and benign, the epidemiological data could be underestimated ${ }^{16}$. Older patients with symptoms suggestive of pSS show a number of typical age-related diagnostic challenges. We have already mentioned causes of Xerostomia which are strongly represented in elderly and it is important to keep an eye on these confounders during a differential diagnosis evaluation. Furthermore, comorbidities and concomitant medications increase iatrogenic Xerostomia risk. ${ }^{17}$ To complete the picture, age related alterations in salivary glands like acinar atrophy, increased fibrotic tissue with ductal dilation, make biopsy interpretation challenging. While acinar atrophy in elderly people could be a physiological aging expression instead of a chronic sialoadenitis, this may very well reduce the number of salivar glands eligible for biopsy.

\section{Clinical picture}

Xerostomia and complications such as dysphagia with food bolus formation and translocation perturbed, dysgeusia with burning sensations and hypersensitivity of the oral mucosa, augmented the risk of developing dental caries, denture problems, speech problems, nocturnal mouth dryness, are all very frequent in SS patients. Speech and eating difficulties can impair social interactions and may cause some patients to reduce social activities. When salivary glands function goes below 50\%, patients show mucosal dryness, cracked and atrophic lips, whiten oral mucosa, and a smooth and inflamed or fissured tongue with loss of some of the dorsal papillae. In patients with SS, the inability of the salivary system to restore oral $\mathrm{pH}$ and regulate bacterial populations often leads to a greater incidence of oral infections; as a matter of fact, compared to non-SS 
controls, one of the most commonly seen oral infections is candidiasis, which develops in $30-70 \%$ of the patients with SS ${ }^{18-20}$. Angular cheilitis may occur more frequently in patients with SS ${ }^{21}$. A visible enlargement of the major salivary glands can occur in patients with salivary obstructions secondary to salivary hypofunction and SS. Older adults have a higher risk to develop an acute parotitis after undergoing extended periods of dehydration and general anaesthesia ${ }^{18}$.

\section{TREATMENT}

SS treatment in elderly and younger patients shows no significant differences, since aims of therapy are common: control of glandular and extra-glandular manifestations, prevention of systemic organ damage, decrease morbidity and mortality, giving the best quality of life.

Preventive measures for ocular dryness include avoidance of exacerbating factors (low-humidity atmospheres and windy locations). Smoke and dust act as irritating factors for eyes and upper airways. Reading or computer use, if prolonged, should be avoided. Drugs that may worsen symptoms of dryness should not be used, if possible. Substitution of saliva and tears is recommended. Mints or sugar-free gums are recommended for patients with dry mouth. Gustatory and masticatory stimulatory techniques (e.g., use of candies that are free of sugar and sugar replacements) are easy to implement and are generally considered harmless. Frequent sips of water during the day and with meals prevent the dry mouth sensation. Muscarinic agonists like Pilocarpine and Cevimeline are effective in the treatment of ocular and oral dryness, if patients have residual functional gland tissue ${ }^{22,23}$.

Oro-mucosal administration of Interferon- $\alpha$ (IFN $\alpha$ ) has been tried, but the initial enthusiasm has been considerably reduced by the most recent studies ${ }^{24}$.

In pSS patients with longer disease duration and lacking residual salivary gland function, anti-CD20 treatment seemed to be effective for systemic features, but no recovery of salivary flow was observed in patients with no, or almost no, residual salivary flow at baseline ${ }^{25}$.

Recently, the European League Against Rheumatism (EULAR) developed two new patient-administrated questionnaires: the EULAR Sjogren's Syndrome Patient Reported Index (or ESSPRI) to assess symptoms, detect disease activity and monitor the effectiveness of therapy, and a disease activity index to evaluate systemic complications, the EULAR SS Disease Activity Index (or ESSDAl) ${ }^{26,27}$.

Finally, treatment in EopSS is challenging and can be complicated by comorbidities, an increased rate of adverse events linked to therapeutic agents, and polypharmacy. For these reasons, careful follow-up of the treatment is required.
Diagnosis of SS in the elderly is a new challenge for physicians. Given the increasing number of elderly people, patients with SS are frequently misdiagnosed and physicians treat each symptom individually, unaware of underlying systemic disease. Improving the awareness around SS is therefore of key importance, given the atypical presentation of autoimmune diseases in the elderly and the fact that early, accurate diagnosis of SS can prevent complications associated with the disease and improve the patient's wellbeing.

\section{DIABETES IN THE ELDERLY}

Diabetes mellitus (DM) is a metabolic disorder characterized by the presence of chronic hyperglycemia associated in many cases with alterations to carbohydrate, protein, and lipid metabolism.

Diabetes is spreading much more year after year, people with diabetes live longer, and, as a result of these two facts, the prevalence of diabetes in the elderly is rising. Older people are nowadays a significant proportion of all patients with diabetes ${ }^{28}$.

Diabetes mellitus relates to many different physical effects on patients; the most frequent oral manifestations related to DM are: dry mouth, tooth decay, periodontal disease and gingivitis, oral candidiasis, burning mouth syndrome (BMS), taste disorders, aspergillosis, oral lichen planus, geographic tongue and fissured tongue, delayed wound healing, and increased incidence of infection, salivary dysfunction, altered taste and other neurosensory disorders, impaired tooth eruption, and benign parotid hypertrophy ${ }^{29}$.

Hyposalivation in oral cavity is associated to functional alterations, morphological changes, and increased susceptibility to other oral pathologies (Tab. IV) ${ }^{30}$.

Many studies have examined the prevalence of oral lesions and xerostomia in patients with diabetes; in one of them, the prevalence of dry mouth was a reported at $76.4 \%{ }^{31}$. The possibility of hyposalivation increases in diabetic patients with low metabolic control, which can cause more severe side effects in relation to oral health. Dry mouth sensation can be referred by people with normal salivary flow; in a study on elder people, the simultaneous existence of both xerostomia and hyposalivation was only $6 \%$, while the prevalence of dry mouth sensation was approximately $20 \%{ }^{32}$.

Xerostomia may be produced by changes in salivary composition instead of changes in salivary quantity ${ }^{33}$.

The change in salivary flow in diabetic patients is even caused by diabetes complications such as neuropathy, angiopathy and metabolic failure, decreasing the activity of the enzymes located in the salivary glands affecting its function. 
Table IV. Signs and symptoms of hyposalivation in the oral cavity (from Gil-Montoya et al., 2016, mod.) ${ }^{30}$.

\begin{tabular}{|l|}
\hline Functional alterations in: \\
\hline chewing \\
\hline flavour \\
\hline swallowing \\
\hline speaking \\
\hline Increased susceptibility to the occurrence of: \\
\hline caries \\
\hline gingivitis \\
\hline spontaneous bleeding \\
\hline periodontitis \\
\hline oral and oropharyngeal infections \\
\hline halitosis \\
\hline ulcers \\
\hline dental plaque formation \\
\hline Morphological changes: \\
\hline dry lips \\
\hline absence of saliva on the floor of the mouth \\
\hline pale and cracked oral mucosa \\
\hline $\begin{array}{l}\text { filiform papilla atrophied and erythematous mucosa on the back of } \\
\text { the tongue }\end{array}$ \\
\hline Other manifestations: \\
\hline pain \\
\hline dry eyes, skin, nose, throat \\
\hline difficulty to wear dental prosthesis \\
\hline
\end{tabular}

In a study conducted by Chavez et al. ${ }^{34}$, a tendency for salivary flow to decrease was observed when $\mathrm{HbA1c}$ values increased. Another study compared the salivary characteristics in 30 patients with diabetes, and the ones of 30 healthy subjects. Eighty per cent of DM patients presented with xerostomia, while only $10 \%$ of healthy subjects presented with it. Furthermore, urea and glucose levels in saliva were significantly higher in diabetics than healthy subjects. This suggests that DM can cause xerostomia and that there may be a significant correlation between the degree of xerostomia and glucose levels in saliva ${ }^{35}$.

The term "quality of life" (QOL) is defined as the patients' feeling of well-being related to various aspects of life. Oral health related quality of life (OHR-QoL) refers to individual feelings of the effects of oral health on the quality of personal life. Patients with diabetes mellitus, compared to healthy people, have a worse quality of life. A descriptive-analytical epidemiological study conducted in 2017 on 200 patients with type 2 diabetes mellitus, showed that xerostomia in diabetic patients has negative effects on oral health related quality of life. It also showed that diabetic control and patients' oral problem improvement is effective in their quality of life promotion ${ }^{36}$.

A study conducted in 2016 on 120 patients affected by DM type 2 (age ranged between 65 and 91 years) assessed salivary flow and its association with xerostomia. Of these, 111 (92.5\%) presented a decrease in salivary flow while 59 (49.2\%) reported moderate to severe xerostomia, so the association between low saliva production and moderate to severe xerostomia observed in this study was not significant ( $p=0.489)$, showing that $x e-$ rostomia is not associated with hyposalivation only. In both genders (insulin dependent and non-insulin dependent patients) severe reduction

of salivary flow was the most prevalent condition, so there were no statistically significant differences between genders or diabetes types ${ }^{38}$.

According to a review conducted in 2016 on studies on therapies of xerostomia, Pilocarpine is the best performing sialogogue drug for subjects with xerostomia due to radiation on head and neck cancer (always where there is some residual function of the parenchyma) or diseases such as SS. In older people, the most common cause of dry mouth is the use of medications with potential xerostomic effects, such as: anticholinergic, sympathomimetic, sedative-hypnotics, opiates, antihistamines and muscle relaxants ${ }^{39}$; the review assessed that the use of malic acid is useful in patients with dry mouth caused by medication. Lubricating drugs of oral mucosa reduce the symptoms, although their effects are short over time ${ }^{30}$

Definitely, the success of different therapeutic strategies for the control of xerostomia, is still not strong enough to recommend a particular treatment, either pharmacological or not. According to a review performed in 2017 , doctors and dentists need to be aware of the various oral manifestations of diabetes in order to make an early diagnosis ${ }^{37}$. Some studies sought a bidirectional relationship in which periodontal diseases could hinder glycaemic control, which confirms the importance of oral care for patients with diabetes ${ }^{40}$.

\section{References}

1 Tanasiewicz M, Hildebrandt T, Obersztyn I. Xerostomia of various etiologies: a review of the literature. Adv Clin Exp Med 2016;25(1):199-206. https://doi.org/10.17219/ acem/29375

2 Ghezzi EM, Lange LA, Ship JA. Determination of variation of stimulated salivary flow rates. J Dent Res 2000;79:18748. https://doi.org/10.1177/00220345000790111001

3 Ship JA, Fox PC, Baum BJ. How much saliva is enough? 'Normal' function defined. J Am Dent Assoc 1991;122:639. https://doi.org/10.14219/jada.archive.1991.0098

4 Ship JA, Pillemer SR, Baum BJ. Xerostomia and the geriatric patient. J Am Geriatr Soc 2002;50:535-43. https://doi. org/10.1046/j.1532-5415.2002.50123.x 
5 Schein OD, Hochberg MC, Munoz B, et al. Dry eye and dry mouth in the elderly: a population-based assessment. Arch Intern Med 1999;159:1359-63. https://doi.org/10.1001/ archinte.159.12.1359

6 Greenlee RT, Murray T, Bolden S, et al. Cancer statistics, 2000. CA Cancer J Clin 2000;50:7-33. https://doi. org/10.3322/canjclin.50.1.7

7 Fox RI, Stern M, Michelson P. Update in Sjögren syndrome. Curr Opin Rheumatol 2000;12:391-8. https://doi. org/10.1097/00002281-200009000-00007

8 Fulop T, Larbi A, Dupuis G, et al. Immunosenescence and inflamm-aging as two sides of the same coin: friends or foes? Front Immunol 2018;10;8:1960. https://doi. org/10.3389/fimmu.2017.01960

9 Mavragani CP, Moutsopoulos HM. Primary versus secondary Sjögren syndrome: is it time to reconsider. J Rheumatol 2019;46;665-6. https://doi.org/10.3899/jrheum.180392

10 Shiboski CH, Shiboski SC, Seror R, et al. 2016 American College of Rheumatology/European League against rheumatism classification criteria for primary Sjögren's syndrome: a consensus and data-driven methodology involving three international patient cohorts. Arthritis Rheumatol 2017;69:35-45. https://doi.org/10.1002/art.39859

11 Vitali C, Del Papa N. Classification and diagnostic criteria in Sjogren's syndrome: a long-standing and still open controversy. Ann Rheum Dis 2017;76:1953-4. https://doi. org/10.1136/annrheumdis-2017-211378

12 Maslinska M, Manzo C. Sindrome di Sjögren primaria nell'anziano: l'età di insorgenza realizza differenze? Giornale Italiano di Reumatologia Clinica 2018;1

13 Ferro F, Marcucci E, Orlandi M, et al. One year in review 2017: primary Sjögren's syndrome. Clin Exp Rheumatol 2017;35:179-91.

14 Patel R, Shahane A. The epidemiology of Sjögren's syndrome. Clin Epidemiol 2014;6:247-55. https://doi. org/10.2147/CLEP.S47399

15 Botsios C, Furlan A, Ostuni P, et al. Elderly onset of primary Sjögren syndrome: clinical manifestations, serological features and oral/ocular diagnostic tests. Comparison with adult and young onset of the disease in a cohort of 336 Italian patients. Joint Bone Spine 2011;78:171-4. https:// doi.org/10.1016/j.jbspin.2010.05.008

16 Drosos AA, Andonopoulos AP, Costopoulos JS, et al. Prevalence of primary Sjögren's syndrome in an elderly population. Br J Rheumatol 1988;27:123-7. https://doi. org/10.1093/rheumatology/27.2.123

17 Wolff A, Joshi RK, Ekström J, et al. A guide to medications inducing salivary gland dysfunction, xerostomia, and subjective sialorrhea: a systematic review. Sponsored by the World Workshop on Oral Medicine VI. Drugs RD 2017;17:128. https://doi.org/10.1007/s40268-016-0153-9

18 Moerman RV1, Bootsma H, Kroese FG, et al. Sjögren's syndrome in older patients: aetiology, diagnosis and management. Drugs Aging 2013;30:137-53. https://doi. org/10.1007/s40266-013-0050-7

19 Soto-Rojas AE, Kraus A. The oral side of Sjögren syndrome. Diagnosis and treatment. A review. Arch Med
Res 2002;33:95-106. https://doi.org/10.1016/s01884409(01)00371-x

20 Zampeli E, Kalogirou EM, Piperi E, et al. Tongue atrophy in Sjögren syndrome patients with mucosaassociated lymphoid tissue lymphoma: autoimmune epithelitis beyond the epithelial cells of salivary glands? J Rheumatol 2018;45:1565-71. https://doi.org/10.3899/ jrheum.180101

21 Guggenheimer J, Moore PA. Xerostomia: etiology, recognition and treatment. J Am Dent Assoc 2003;134:61-9. https://doi.org/10.14219/jada.archive.2003.0018

22 Papas AS, Sherrer YS, Charney M, et al. Successful treatment of dry mouth and dry eye symptoms in Sjögren's syndrome patients with oral pilocarpine: a randomized, placebo-controlled, dose-adjustment study. J Clin Rheumatol 2004;10:169-77. https://doi.org/10.1097/01.rhu.0000135553.08057.21

23 Petrone D, Condemi JJ, Fife R, et al. A double-blind, randomized, placebo-controlled study of cevimeline in Sjögren's syndrome patients with xerostomia and keratoconjunctivitis sicca. Arthritis Rheum 2002;46:748-54. https://doi.org/10.1002/art.510

24 Khurshudian AV. A pilot study to test the efficacy of oral administration of interferon-alpha lozenges to patients with Sjögren's syndrome. Oral Surg Oral Med Oral Pathol Oral Radiol Endod 2003;95:38-44. https://doi.org/10.1067/ moe.2003.30

25 Meijer JM, Pijpe J, Vissink A, et al. Treatment of primary Sjogren syndrome with rituximab: extended follow-up, safety and efficacy of retreatment. Ann Rheum Dis 2009;68:284-5. https://doi.org/10.1136/ard.2008.092601

26 Vitali C, Palombi G, Baldini C, et al. Sjögren's syndrome disease damage index and disease activity index: scoring systems for the assessment of disease damage and disease activity in Sjögren's syndrome, derived from an analysis of a cohort of Italian patients. Arthritis Rheum 2007;56:2223-31. https://doi.org/10.1002/art.22658

27 Seror R, Rauz S, Gosset M, et al. Disease activity and patient reported outcome measures in Sjögren's - what are the best tools to evaluate? Rheumatology (Oxford) 2019. https://doi.org/10.1093/rheumatology/kez201 [Epub ahead of print].

28 Sanjay K, Sharma SK. Diabetes in the Elderly. Diabetes Ther Res Treat Educ Diabetes Relat Disord 2018;9,2:493500. https://doi.org/10.1007/s13300-018-0380-x.

29 Albert DA, Ward A, Allweiss P, et al. Diabetes and oral disease: implications for health professionals. Ann N Y Acad Sci 2012;1255:1-15. https://doi.org/10.1111/j.17496632.2011.06460.x

30 Gil-Montoya JA, Silvestre F-J, Barrios R, et al. Treatment of xerostomia and hyposalivation in the elderly: a systematic review. Med Oral Patol Oral Cir Bucal 2016;21:e355-66. https://doi.org/10.4317/medoral.20969

31 Mauri-Obradors E, Estrugo-Devesa A, Jané-Salas E, et al. Oral manifestations of diabetes mellitus. A systematic review. Med Oral Patol Oral Cir Bucal 2017;22:e586-94. https://doi.org/10.4317/medoral.21655

32 Narhi TO. Prevalence of subjective feelings of dry mouth in 
the elderly. J Dent Res 1994;73:20-5. https://doi.org/10.1 177/00220345940730010301. PMID: 8294614

33 Busato IM, Ignácio SA, Brancher JA, et al. Impact of clinical status and salivary conditions on xerostomia and oral health-related quality of life of adolescents with type 1 diabetes mellitus. Community Dent Oral Epidemiol 2012;40:629. https://doi.org/10.1111/j.1600-0528.2011.00635.x

${ }^{34}$ Chávez EM, Borrell LN, Taylor GW, et al. A longitudinal analysis of salivary flow in control subjects and older adults with type 2 diabetes. Oral Surg Oral Med Oral Pathol Oral Radiol Endod 2001;91:166-73. https://doi.org/10.1067/ moe.2001.112054

35 Ivanovski K, Naumovski V, Kostadinova M, et al. Xerostomia and salivary levels of glucose and urea in patients with diabetes. Pril/Makedon Akad na Nauk i Umet Odd $\neg$ elenie za biološki i Med Nauk = Contrib/Maced Acad Sci Arts, Sect Biol Med Sci 2012;33:219-29.

36 Molania T, Alimohammadi M, Akha O, et al. The effect of xerostomia and hyposalivation on the quality of life of patients with type II diabetes mellitus. Electronic Physician 2017;9:5814-9. https://doi.org/10.19082/5814

37 Mauri-Obradors E, Estrugo-Devesa A, Jané-Salas E, et al. Oral manifestations of diabetes mellitus. A systematic review. Med Oral Patol Oral Cir Bucal 2017;22:e586-94. http://dx.doi.org/doi:10.4317/medoral.21655

38 Lima DLF, Carneiro SDRM, Barbosa FTdS, et al. Salivary flow and xerostomia in older patients with type 2 diabetes mellitus. PLoS One 2017;12:e0180891. https://doi. org/10.1371/journal.pone.0180891

39 Scully C. Drug effects on salivary glands: dry mouth. Oral Dis 2003;9:165-76. https://doi.org/10.1034/j.16010825.2003.03967.x

40 Costa KL, Taboza ZA, Angelino GB, et al. The influence of periodontal disease on changes of glycated hemoglobin levels in type 2 diabetics: a retrospective cohort study. J Periodontol 2016 26:1-13. https://doi.org/10.1902/ jop.2016.160140 